$\mathbb{T}$ Periodica Polytechnica Civil Engineering

60(3), pp. 455,469. 2016

DOI: $10.3311 /$ PPci.7800

Creative Commons Attribution (1)

RESEARCH ARTICLE

\section{Suitability of}

\section{Flyash-Lime-Phosphogypsum Composite in Road Pavements}

\author{
Rakesh Kumar Dutta, Vaibhav Kumar
}

Received 07-11-2014, revised 07-05-2015, accepted 20-04-2015

\section{Abstract}

The paper presents the suitability of flyash-limephosphogypsum composite for its use in road pavements. The content of lime and phosphogypsum was varied from 2 to $10 \%$ and 0.5 to $4 \%$ respectively in flyash. The specimen prepared was cured for 7, 28, 56 and 90 days with burlap method of curing. Compaction tests were conducted on different flyash-lime-phosphogypsum composite and these results were used for casting cylindrical specimens for unconfined compressive strength, split tensile strength, slake durability and for determination of bearing ratio. It has been concluded that flyash-lime-phosphogypsum composite satisfy the unconfined compressive strength, split tensile strength, slake durability criteria as well as giving higher bearing ratio values at 28 days of curing. Good agreement is observed between the experimental values and predicted values for tensile strength, bearing ratio, slake durability indices. The developed models will be useful for making preliminary estimate of these parameters by the field engineers for planning purposes. The empirical models presented are based on the experimental data within the range of parameter (curing period 7 to 90 days) and materials tested. Beyond this range of values the model may be checked with experimental results. The models reported in literature under estimate the properties like bearing ratio, tensile strength and slake durability indices determined from the unconfined compressive strength. The flyash-lime-phosphogypsum composite (flyash $+8 \%$ lime $+2 \%$ phosphogypsum) cured for 28 days can be used as a base/subbase course material in road pavements.

\section{Keywords}

Flyash $\cdot$ Lime $\cdot$ Phosphogypsum $\cdot$ Compaction $\cdot$ Unconfined compressive strength $\cdot$ Tensile strength $\cdot C B R \cdot$ Slake durability $\cdot$ SEM $\cdot X R D \cdot$ Correlation

\section{Rakesh Kumar Dutta}

Professor, Department of Civil Engineering, National Institute of Technology, Hamirpur - 177005, Himachal Pradesh, India

e-mail: rakeshkdutta@yahoo.com

\section{Vaibhav Kumar}

PG Student, Department of Civil Engineering, National Institute of Technology, Hamirpur - 177005, Himachal Pradesh, India

\section{Introduction}

Most developed and developing countries all over the world have huge resources of waste materials such as fly ash and phosphogypsum (a waste produced during the manufacturing of phosphoric acid). These waste materials contain large quantities of impurities which may pollute the subsoil or ground water if disposed off in an open environment. The quantities of these waste materials produced around the world are huge and causing disposal problems that are both financially and environmentally expensive. One method to reduce some portion of the flyash and phosphogypsum disposal problem is by mixing them together in the presence of stabilizer like lime and utilizing the composite so produced for civil engineering applications. Further, in India, extensive road network is under construction. Civil engineers around the world are in search of new alternative materials which are required both for cost effective solution for roads and for conservation of scarce natural resources. In this context, flyash-lime-phosphogypsum, hold promise as alternate materials for application in roads.

\section{Background}

There are numerous laboratory studies on fly ash alone or mixed with lime, gypsum or in combination. Addition of lime to the low lime flyash results marginal increase in dry unit weight and optimum moisture content [1]. Addition of gypsum in fly ash mix decreases the dry unit weight of the mix as compared to that without gypsum [2] whereas the optimum moisture content varied from 31.5 to $35.4 \%$ and maximum dry unit weight varied from 10.25 to $10.82 \mathrm{kN} / \mathrm{m}^{3}$ [3]. Standard Proctor tests on the Class $\mathrm{F}$ pond ash mixed with varying percentages of lime $(4,6$, and $10 \%)$ and phosphogypsum $(0.5$, and $1.0 \%)$ reported the optimum moisture content and dry unit weight varied from 33.23 to $29.07 \%$ and 11.43 to $11.83 \mathrm{kN} / \mathrm{m}^{3}$ respectively [4]. Various investigators [5-7] studied the enhancement of the strength of fly ash as a result of actions between fly ash and lime. It was pointed out by [8] that the pozzolanic reaction between fly ash and lime is complex, very slow and takes a long time to gain considerable strength whereas researchers [9, 10] reported that the increase in strength with the addition of lime to the fly 
ash may not be sufficient for certain applications. The strength of the flyash-lime matrix would depend on the amount of lime available for pozzolanic reaction [11]. Addition of gypsum in fly ash supply the sulphate ions which react with the alumina present in the fly ash and causes dissociation of the glass structure [12]. The sulphate in fly ash causes the formation of more dense hydrate structure and leads to the increase in strength [13]. Addition of $1 \%$ gypsum along with $10 \%$ lime to the fly ash enhanced the unconfined compressive strength by 36.7 times [14]. It was further in this study that the improvement in unconfined compressive strength is due to fly ash lime reaction as well as the catalyzing effect of gypsum. The gain in strength with curing period for high calcium fly ash is very high compared to that of low calcium fly ash due to presence of reactive minerals and glassy phase [15]. Addition of small percentages of gypsum 0.5 or $1.0 \%$ to fly ash lime mix increased the strength of compacted specimens at lower curing period ( 7 days) compared to only lime stabilized mixes [16]. It was further mentioned in this study that the contribution of gypsum is significant for curing periods up to 45 days and increases with increase in gypsum content from 0.5 to $1.0 \%$. But at a higher curing period ( 90 days), the contribution of gypsum is comparatively less. Tensile strength is a vital parameter to judge the suitability of a stabilized fly ash when it is provided to serve as a base course material in road construction. A stabilized pavement layer is subjected to repeated tensile stresses due to traffic load and failure is initiated due to the formation and propagation of tensile cracks [17]. The stabilized layer may also be subjected to tensile stress due to differential ground movement caused by seasonal variations and temperature gradients. The split tensile strength of flowable high volume fly ash cement composite, lightly cemented sand and compacted soil fly ash carbide lime mixtures was reported by [18-20]. Generally a recycled construction material should satisfy the requirements of strength [21]. The tensile strength of a class F fly ash stabilized with lime (4, 6, and 10\%) alone or in combination with gypsum (0.5 to $1.0 \%)$ varied between 309 and $1,084 \mathrm{kPa}$ for 45 days curing [16]. One of the most important properties that the stabilized mixes should have is the ability to retain its strength over the year when exposed to the destructive forces of weather. One of the most commonly used durability tests on stabilized mixes in a non-frost area is wetting and drying test. It was highlighted by [14,22] that durability of stabilized specimens is one of the most important property for any construction material. Addition of fly ash to soil-lime mixture increases the durability [23]. It was further mentioned in this study that the durability requirement was satisfied after 28 days curing with a lime content of 10\%. Many investigators [24,25] studied the durability of stabilised materials through slake durability tests. The effects of lime content (4, 6, and 10\%), gypsum content ( 0.5 and $1.0 \%$ ), and curing period (up to 90 days) on the slake durability characteristics of class F fly ash reported that unstabilized fly ash samples and samples stabilized with $4 \%$ lime does not even last for first cycle at all the curing pe- riods whereas, additions of small percentages of gypsum $(0.5$ and $1.0 \%$ ) in fly ash-lime mixes improved the durability characteristics at 28 days of curing [16]. Slake durability test on the fly ash, lime and gypsum mixes in order to assess the resistance offered by a fly ash mix to weakening and disintegration when subjected to two standard cycles of drying and cooling on specimen cured for 28 and 56 days reported that slake durability index for fly ash mix without gypsum varied from $96 \%$ to $97 \%$ during the 1 st cycle for 28 days cured specimen and increased marginally for 56 days cured specimen [2]. Wetting and drying test on fly ash-lime-gypsum mixes reported no significant reduction in the strength of the fly ash-lime-gypsum mixes even after 20 cycles of wetting and drying [1]. Addition of phosphogypsum in fly ash-lime mixes improves the durability characteristics [26]. The effect of temperature on the durability study on the fly ash mixed with fluorogypsum, hydrated lime sludge mixed with/ without Portland cement concluded a decrease in the durability with the increase in temperature [27]. The bearing ratio tests on fly ash-lime mixes and reported that the bearing ratio can be increased with the addition of small percentages of gypsum $(0.5$ and $1.0 \%$ ) [16]. It was further mentioned in this study that the bearing ratio of the unsoaked specimens containing $10 \%$ lime and $1.0 \%$ gypsum and cured for 28 days was $172 \%$ in comparison to $34 \%$ for unstabilized fly ash at the same curing period. Further, hardly any literature is available to study the suitability of fly ash-lime-phosphogypsum composite for possible use in roads. In the present work, the compaction, unconfined compressive strength, and tensile strength, slake durability and California bearing ratio of fly ash-lime-phosphogypsum composite are assessed for possible application in roads and finally correlations are proposed among the properties studied which shall be useful for the field engineers for making preliminary estimate for planning purposes.

\section{Materials Used and Experimental Procedure}

The flyash used in this investigation was having a specific gravity of 2.04. The dry unit weight and optimum water content as obtained by standard proctor test was found to be $11.36 \mathrm{kN} / \mathrm{m}^{3}$ and $26.0 \%$ respectively. The $X R D$ and $S E M$ of fly ash are shown in Fig. 11(a) and Fig. 2. a) respectively.

Commercially available lime was used in the present study. The XRD and SEM of lime are shown in Fig. 1 (b) and Fig. 2(b) respectively. Fig. 1(b) indicates prominent calcium hydroxide peaks along with a few quartz and calcite peaks. The phosphogypsum was procured from Khanna, Punjab, India. The X-ray diffraction and SEM of phosphogypsum is shown in Fig. 1 (c) and Fig. 2(c) respectively. Fig. 1.c) indicates prominent gypsum peaks. The chemical analysis of the phosphogypsum supplied by the supplier indicates that it contains 92 to $95 \% \mathrm{CaSo}_{4}$. The content of lime and phosphogypsum was varied from 2 to $8 \%$ and 0.5 to $4 \%$ respectively. The standard proctor compaction tests were conducted as per [28] on flyash-lime-phosphogypsum mixtures and water was added as needed to facilitate the mix- 


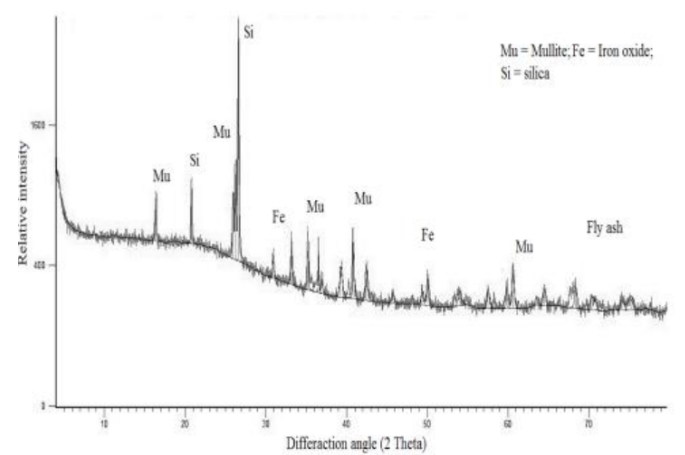

(a)

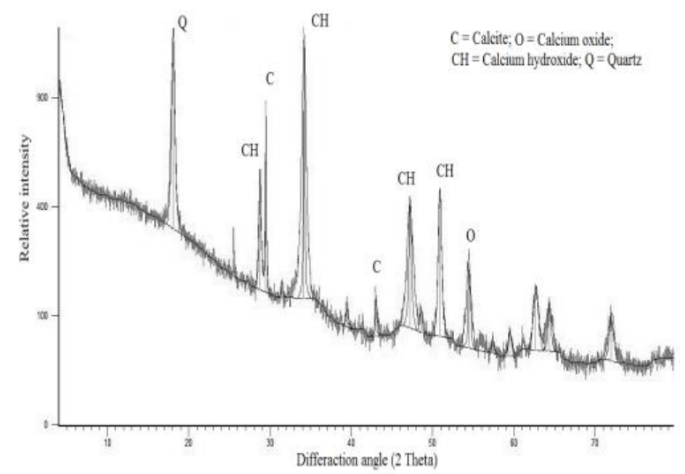

(b)

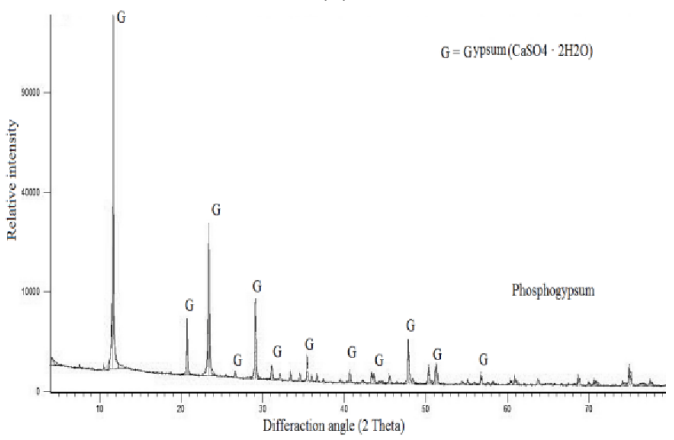

(c)

Fig. 1. X- Ray diffractogram of(a) fly ash(b) lime(c) phosphogypsum

ing and compaction process. For the unconfined compressive strength and split tensile strength tests, the fly ash was ground lightly by hand with a pestle to separate the individual particles. A metallic mould having size $50 \mathrm{~mm}$ inner diameter and $100 \mathrm{~mm}$ long for unconfined compressive strength test and $50 \mathrm{~mm}$ inner diameter and $25 \mathrm{~mm}$ long for the split tensile strength test, with additional detachable collars at both ends were used to prepare cylindrical specimens. The required quantities of fly ash, lime, phosphogypsum was mixed in dry state and required quantity of water (corresponding to OMC) was added to it. To ensure uniform compaction, specimen was compressed statically from both ends till the specimen just reached the dimensions of the mould. Then the specimen was extracted with the hydraulic jack and was allowed to dry at room temperature. The dried specimens were cured for 7, 28, 56 and 90 days using a burlap method of curing. After the desired period of curing, the specimen was tested for unconfined compressive strength and split tensile strength using a strain rate of $0.24 \mathrm{~mm} / \mathrm{min}$. Proving rings of ca-

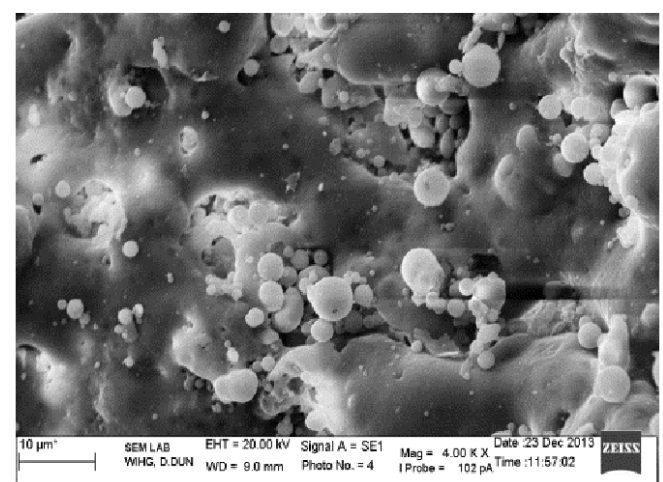

(a)

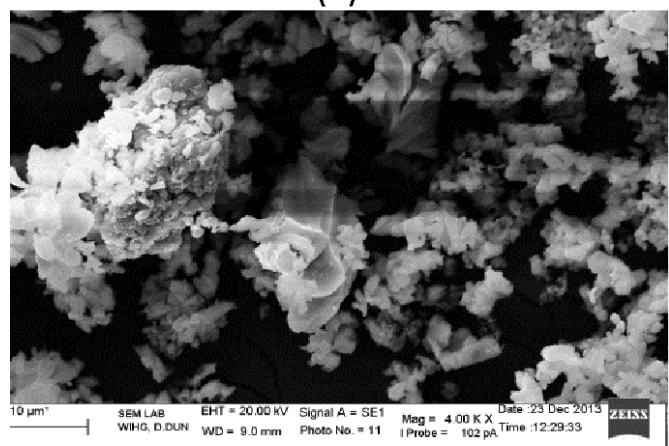

(b)

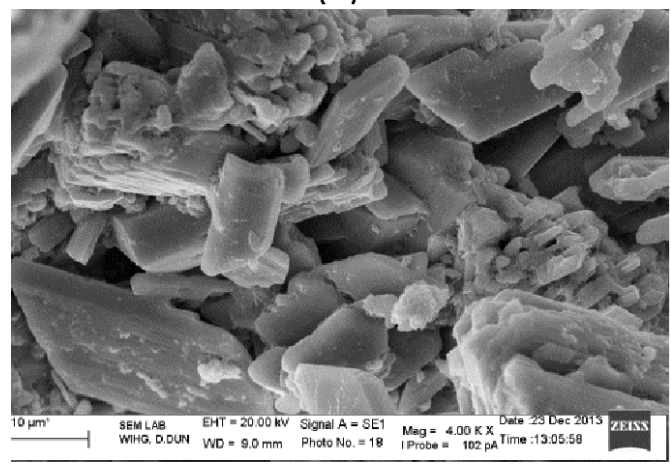

(c)

Fig. 2. SEM of(a) fly ash $(20 \mathrm{KV}, \mathrm{X} 4000,10 \mu)(\mathrm{b})$ lime $(20 \mathrm{KV}, \mathrm{X} 4000$, $10 \mu)(c)$ phosphogypsum $(20 \mathrm{KV}, \mathrm{X} 4000,10 \mu)$

pacity $25 \mathrm{kN}$ and $100 \mathrm{kN}$ were used for testing specimens cured for 7 days and 28, 56, 90 days respectively. The failed specimens after performing unconfined compressive strength were preserved in air tight polythene covers for XRD and SEM tests. Stabilized materials used in the road pavements are subjected to destructive forces such as alternate wetting \& drying, heating \& cooling and frost susceptibility in the field. Therefore the stabilized materials used in road pavements should have adequate durability against these forces. The durability of flyash-limephosphogypsum composites is assessed through slake durability test on cylindrical specimens (38 $\mathrm{mm}$ dia and $76 \mathrm{~mm}$ high) cured for required number days as per [29]. For California bearing ratio tests on flyash-lime-phosphogypsum composite, a thin layer of grease was applied on the internal surfaces of the CBR mould in an attempt to minimize the side friction. The flyashlime-phosphogypsum were compacted on the top of the CBR mould (rigid metal cylinder with an inside diameter of $152 \mathrm{~mm}$ and a height of $178 \mathrm{~mm}$ ) at a respective optimum moisture con- 
tent by the standard procedure by giving 56 blows of a $25.5 \mathrm{~N}$ rammer dropped from a distance of $310 \mathrm{~mm}$. The prepared specimen inside the mould was then wrapped in the burlap for curing for required number of days. A manual loading machine equipped with a movable base that travelled at a uniform rate of $1.2 \mathrm{~mm} / \mathrm{min}$ and a calibrated load-indicating device was used to force the penetration piston of diameter of $50 \mathrm{~mm}$ into the cured specimen in the mould. A surcharge plate of $2.44 \mathrm{kPa}$ was placed on the specimen prior to testing. The loads were carefully recorded as a function of penetration up to a total penetration of $12.5 \mathrm{~mm}$.

\section{Testing Results and Analyses}

\subsection{Compaction}

Studies were carried out to pick up the optimum mix for fly ash stabilized with lime. The content of lime was varied from $2 \%$ to $10 \%$ by dry weight of fly ash. The standard proctor compaction tests were conducted as per [28] The results are shown in Fig. 3 a). Fig. 3 a) also contains the compaction curve for the fly ash. Study of Fig. 3. a) reveals that the dry unit weight of the flyash was $11.36 \mathrm{kN} / \mathrm{m}^{3}$ which increased to $11.38 \mathrm{kN} / \mathrm{m}^{3}$ with the addition of $2 \%$ lime. The dry unit weight further increased to $11.53 \mathrm{kN} / \mathrm{m}^{3}, 11.58 \mathrm{kN} / \mathrm{m}^{3}, 11.79 \mathrm{kN} / \mathrm{m}^{3}$ respectively with the addition of $4,6,8 \%$ lime to the fly ash. Fig. 3.a) further reveals that the optimum moisture content of the flyash was $26 \%$ which increased to $27.78 \%$ with the addition of $2 \%$ lime.

The optimum moisture content further increased to 28.11 , $28.25,29.10$ and $30.12 \%$ with the addition of $4,6,8$, and $10 \%$ lime to the flyash. Similar observations in respect of dry unit weight and optimum moisture content for the flyash-limegypsum mixture were reported by [30] A close examination of Fig. 3 (a) reveals that the dry unit weight decreased beyond a lime content of $8 \%$ in fly ash. On the basis of the compaction study reported above, a mix of flyash $+8 \%$ lime was chosen for further study. The compaction curves for fly ash $+8 \%$ lime mix mixed with varying percentage of phosphogypsum $(0.5 \%$ to $4 \%$ by dry weight of fly ash) are shown in Fig. 3 b). A study of Fig. 3. b) reveals that the dry unit weight of fly ash $+8 \%$ lime was $11.79 \mathrm{kN} / \mathrm{m}^{3}$ which increased to $11.92 \mathrm{kN} / \mathrm{m}^{3}, 11.97 \mathrm{kN} / \mathrm{m}^{3}$ and $12.09 \mathrm{kN} / \mathrm{m}^{3}$ with the addition of $0.5,1$ and $2 \%$ phosphogypsum. Similar observations in respect of dry unit weight for the flyash-lime mix with varying percentage of gypsum were reported by [30]. Beyond a phosphogypsum content of $2 \%$, the dry unit weight marginally dipped to $12.01 \mathrm{kN} / \mathrm{m}^{3}$. Similar observations were reported by [2] where a decrease in dry unit weight of the fly ash-lime mix was observed with the addition of $5 \%$ gypsum. Fig. 3 (b) further reveals that the optimum moisture content of the flyash $+8 \%$ lime with varying percentage of phosphogypsum ( 0.5 to $4 \%$ by dry weight of fly ash) ranged from 24.1 to $25.1 \%$ but the values of moisture content were less in comparison to flyash $+8 \%$ lime mix. This part of the study is carried out to validate the previous findings. Based upon the compaction studies reported above, a reference mix of fly ash

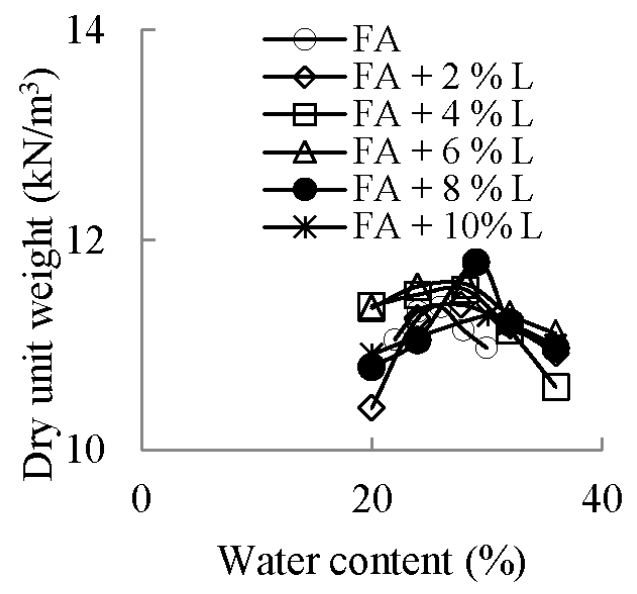

(a)

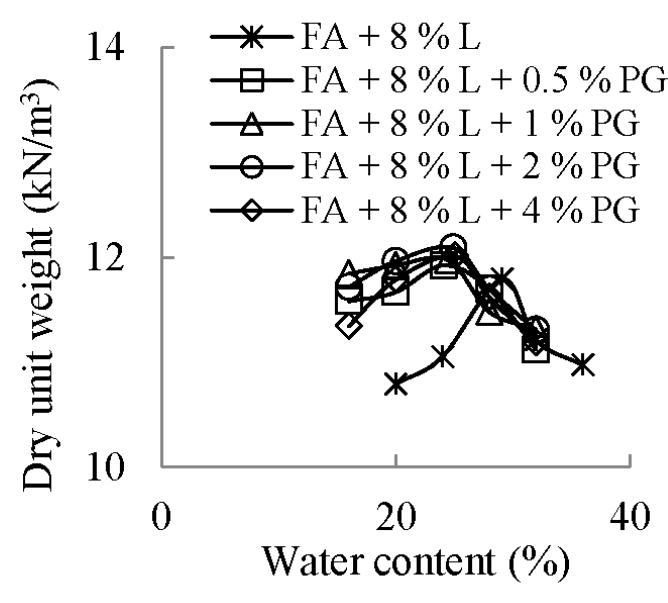

(b)

Fig. 3. Compaction curves (a) for fly ash stabilized with lime (b) fly ash stabilized with $8 \%$ lime and varying content of phosphogypsum

$+8 \%$ lime $+2 \%$ phosphogypsum was selected for the further experimental work.

\subsection{Unconfined Compressive Strength}

Typical axial stress-strain curves obtained are presented in Fig. 4 and the variation of the unconfined compressive strength with curing is shown in Fig. 5

Study of Fig. 5 reveals that the unconfined compressive strength increases significantly with the increase in curing period. The unconfined compressive strength of the reference mix at 7 days of curing was $513.74 \mathrm{kPa}$ which increased to $2193.87 \mathrm{kPa}, 2554.39 \mathrm{kPa}$ and $2920.23 \mathrm{kPa}$ for 28,56 and 90 days of curing respectively. Further study of Fig. 5 reveals that there is slow improvement in unconfined compressive strength from 56 days to 90 days. The 7-day unconfined compressive strength for gravelly and sandy soil is adopted by Association of American State Highway and Transportation Officials (AASHTO) is varying between $2072.9 \mathrm{kPa}$ to $4144.7 \mathrm{kPa}$. The 7-day unconfined compressive strength of soil-cement mixes to be varying between $1765.8 \mathrm{kPa}$ to $3384.5 \mathrm{kPa}$ as reported by 


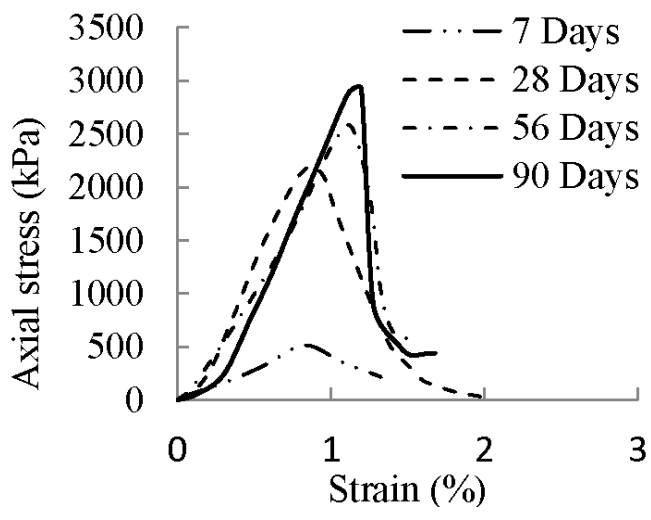

Fig. 4. Stress-strain curves for unconfined compressive strength of the reference mix with curing period

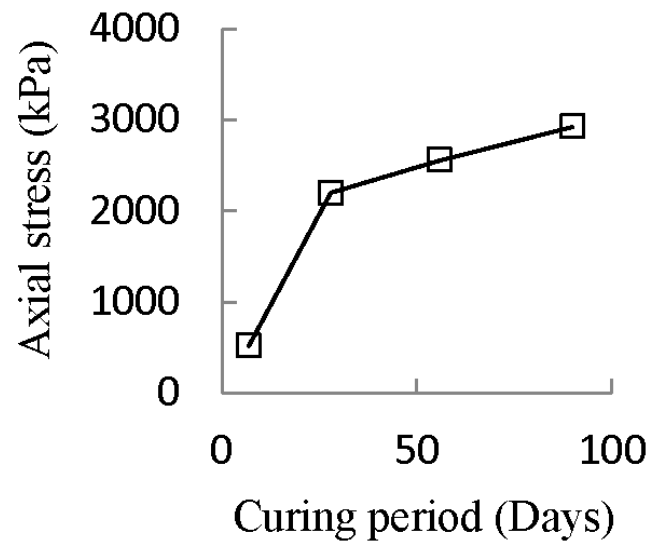

Fig. 5. Variation of unconfined compressive strength for the reference mix with curing period

[31]. The unconfined compressive strength of the reference mix at 28 days of curing is $2193.87 \mathrm{kPa}$ which falls in between these two criteria. Thus the reference mix satisfies the requirement of the unconfined compressive strength at 28 days of curing.

\subsection{Tensile Strength}

Various tests and modifications have been developed and used for evaluating tensile strengths of stabilized soils e.g. direct tensile, bending, and double punch tensile and Brazilian split tensile strength test. However, out of all these methods, the Brazilian split tensile test has been widely used for the determination of indirect tensile strength by different investigators [16, 19] and [32].

Typical tensile stress- diametral strain curves obtained are presented in Fig. 6 and the variation of the tensile strength with curing period is shown in Fig. 7. Study of Fig. 7 reveals that the tensile strength increases significantly with the increase in curing period. The tensile strength of the reference mix at 7 days of curing was $151.32 \mathrm{kPa}$ which increased to $827.87 \mathrm{kPa}$, $1942.73 \mathrm{kPa}$ and $2298.62 \mathrm{kPa}$ for 28,56 and 90 days of curing respectively. Minimum requirement of indirect tensile strength at 7 days of moist curing for heavily trafficked roads was $80 \mathrm{kPa}$ as reported by [33]. The tensile strength of the reference mix at 7 and 28 days of curing is $151.32 \mathrm{kPa}$ and $827.87 \mathrm{kPa}$ respectively. The observed values of tensile strength for reference mix

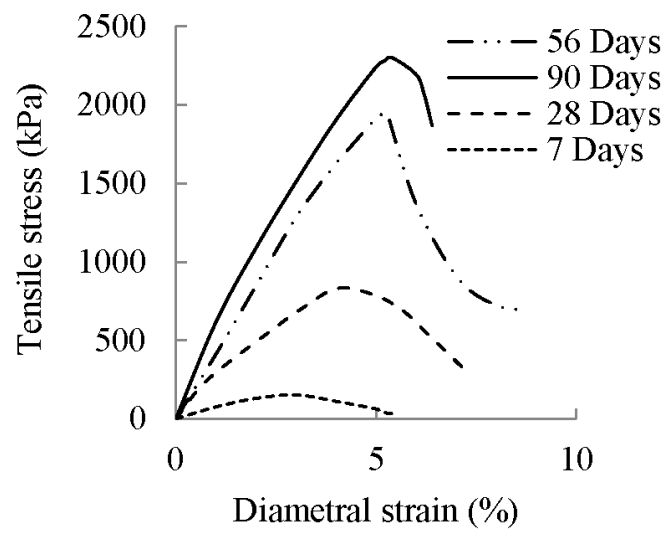

Fig. 6. Tensile stress-Diametral strain curves for the reference mix with curing period

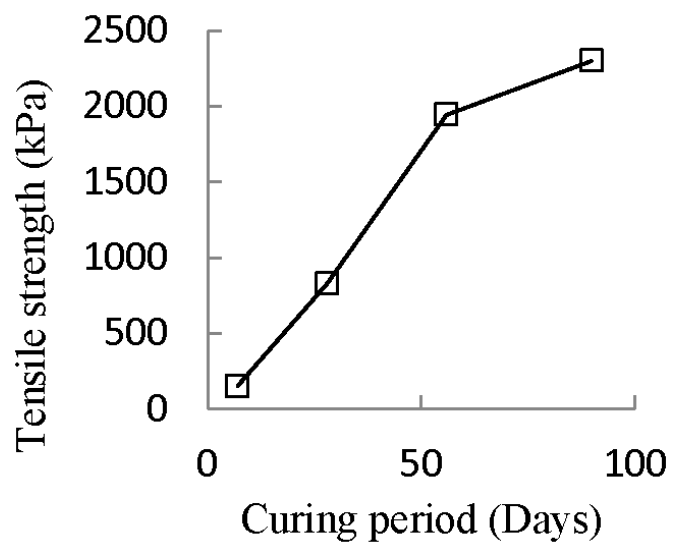

Fig. 7. Variation of tensile strength for the reference mix with curing period

at 7 and 28 days of curing were found to be much higher than the minimum indirect tensile strength value of $80 \mathrm{kPa}$ reported by [33]. Thus the reference mix satisfies the requirement of the tensile strength at 7 days of curing. In the absence of models for predicting the tensile strength at failure for the flyash-limephosphogypsum composite, it was thought pertinent to check the validation of the empirical model (Eq. (1)) proposed for flyash-lime-gypsum mix by [16] on the experimental results obtained in the present study.

$$
T S=0.0273 * q u^{1.19832}
$$

The results are shown in Fig. 8 for the reference mix cured with burlap method of curing. It is evident from this figure that predicted values of tensile strength are less than the tensile strength obtained in the current study. This under estimation of the tensile strength using empirical model reported by [16] is attributed to the difference in curing procedure adopted and materials used.

\subsection{Slake Durability}

Gamble's slake durability classification summarized by [34] is shown in Table 1 and slake durability indices $\mathrm{I}(\mathrm{d}) 1$ and $\mathrm{I}(\mathrm{d}) 2$ of the reference mix cured for $7,28,56$, and 90 days are tabulated in Table 2. Study of Table 2 reveals that the reference mix cured for 7 days was having medium durability which im- 


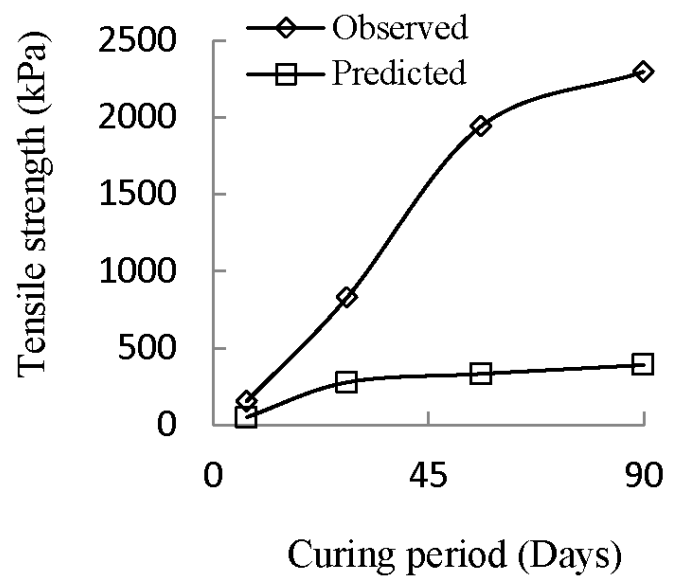

Fig. 8. Variation of predicted and observed tensile strength with curing period for the reference mix cured with burlap curing method

proved to medium high durability at the end of 28 days of curing. The durability further improved to high durable and very high durable once the curing period is increased to 56 and 90 days respectively. This increase in the durability of the reference mix with the increase in curing period is

Tab. 1. Gamble's slake durability classification

\begin{tabular}{ccc}
\hline \multicolumn{3}{c}{ Gamble's slake durability classification } \\
\hline $\mathrm{I}(\mathrm{d}) 1(\%)$ & $\mathrm{I}(\mathrm{d}) 2(\%)$ & Durability \\
\hline$>99$ & $>98$ & Very high durable \\
$98-99$ & $95-98$ & High durable \\
$95-98$ & $85-95$ & Medium high durable \\
$85-95$ & $60-85$ & Medium durable \\
$60-85$ & $30-60$ & Low durable \\
$<60$ & $<30$ & Very low durable \\
\hline
\end{tabular}

Tab. 2. Slake durability indices I (d)1 and I (d)2

\begin{tabular}{cccc}
\hline & & & $\begin{array}{c}\text { Assessment of } \\
\text { durability } \\
\text { Curing period (Days) }\end{array}$ \\
& $\mathrm{I}(\mathrm{d}) 1$ & $\mathrm{I}(\mathrm{d}) 2$ & $\begin{array}{c}\text { as per Gamble's } \\
\text { slake durability } \\
\text { classification }\end{array}$ \\
\hline 7 & 85.50 & 82.21 & Medium durable \\
28 & 95.51 & 85.26 & Medium high durable \\
56 & 98.56 & 95.49 & High durable \\
90 & 99.52 & 98.10 & Very high durable \\
\hline
\end{tabular}

Variation of predicted and observed(a) slake durability index $\mathrm{I}(\mathrm{d})_{1}$ and(b) slake durability index $\mathrm{I}(\mathrm{d})_{2}$ with curing period for the reference mix cured with burlap curing method

attributed to the formation of pozzolanic reaction products in the reference mix containing flyash-lime-phosphogypsum. For the flyash-lime-gypsum mixture cured for 28 days for use as base/subbase materials in roads, a medium durable to medium high durable material is required as recommended by [16]. The reference mix containing flyash-lime-phosphogypsum and cured for 28 days was having medium high durability which satisfies the requirement reported by [16] for its use as base/subbase material. In the absence of models for predicting

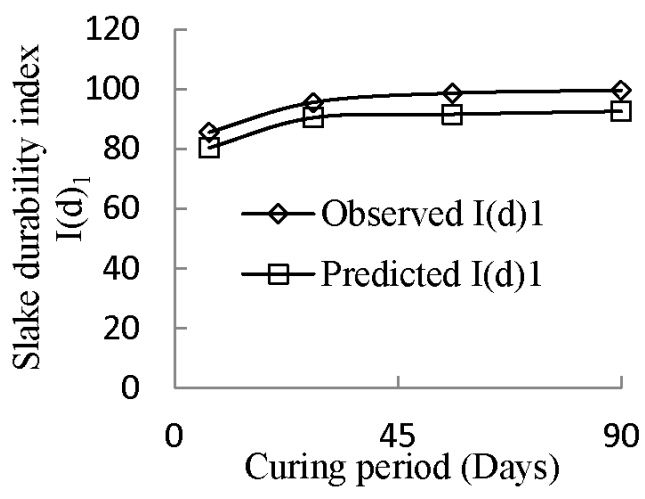

(a)

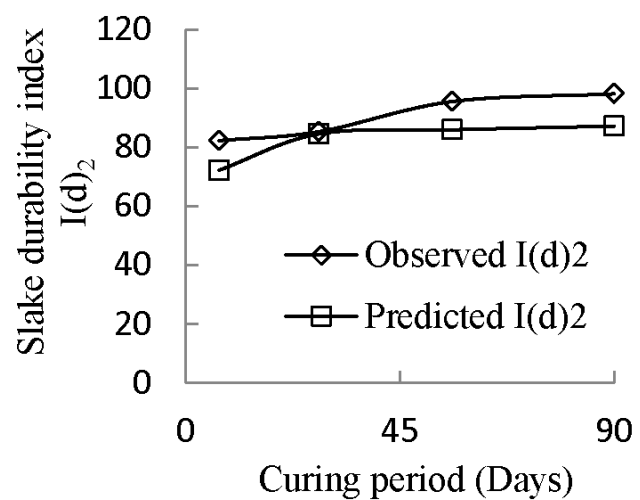

(b)

Fig. 9. Variation of predicted and observed (a) slake durability index I(d) 1 and (b) slake durability index I(d) 2 with curing period for the reference mix cured with burlap curing method

the slake durability indices $\mathrm{I}(\mathrm{d})_{1}$ and $\mathrm{I}(\mathrm{d})_{2}$ for the flyash-limephosphogypsum composite, it was thought pertinent to check the validation of the empirical models (Eq. (2)) and (Eq. (3)) respectively) proposed for flyash-lime-gypsum mix by [16] on the experimental results obtained in the present study.

$$
\begin{aligned}
& I(d) 1=48.313 * q u^{0.0814} \\
& I(d) 2=36.667 * q u^{0.1085}
\end{aligned}
$$

The results are shown in Fig. 9 for the reference mix cured with burlap method of curing. It is evident from these figures that predicted values of slake durability indices $I(d)_{1}$ and $I(d)_{2}$ is less than the slake durability indices $\mathrm{I}(\mathrm{d})_{1}$ and $\mathrm{I}(\mathrm{d})_{2}$ obtained in the current study. This under estimation of the slake durability indices $\mathrm{I}(\mathrm{d})_{1}$ and $\mathrm{I}(\mathrm{d})_{2}$ using [16] empirical model is attributed to the difference in curing procedure adopted and materials used.

\subsection{California Bearing Ratio}

Typical load deformation curves for bearing ratio of the reference mix cured for 7, 28, 56 and 90 days are presented in Fig. 10 and variation in the bearing ratio with the curing period is shown in Fig. 11 .

Study of Fig. 11 reveals that the bearing ratio increases significantly with the increase in curing period. For example, the bearing ratio of the reference mix at 7 days of curing corresponding to a deformation of $2.5 \mathrm{~mm}$ was $70.16 \%$ which increased to 


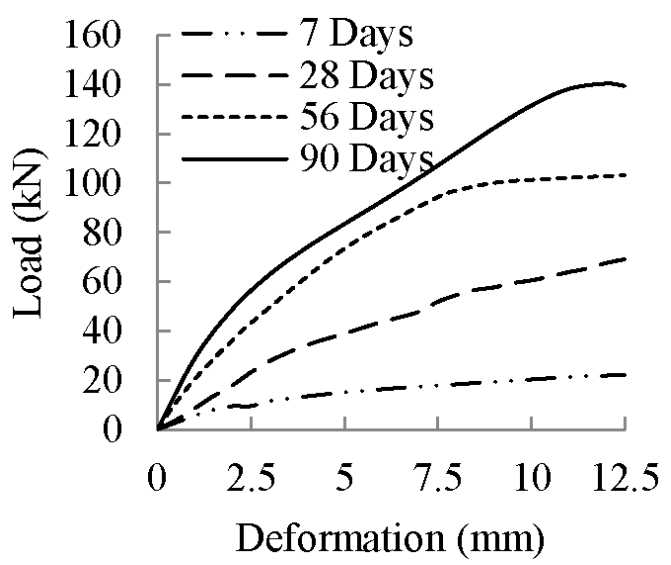

Fig. 10. Load-deformation curves for the reference mix at different curing period

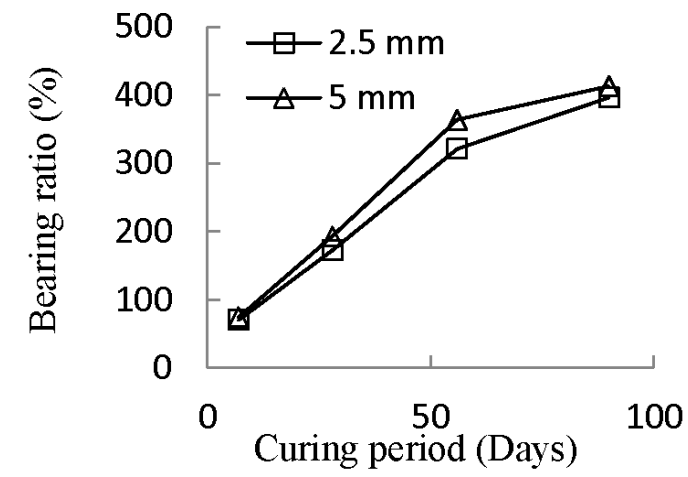

Fig. 11. Variation of bearing ratio for the reference mix with cuing period

$172.10 \%, 320.91 \%$ and $396.06 \%$ for 28,56 and 90 days of curing respectively at the same deformation. The values of bearing ratio at a deformation of $5 \mathrm{~mm}$ for the reference mix cured for 7 days was $74.21 \%$ which increased to $192.66 \%, 363.55 \%$ and $412.80 \%$ at the end of 28,56 and 90 days of curing respectively. It has been specified by [35] that a minimum bearing ratio of more than $80 \%$ is required for base materials, $30-80 \%$ for subbases, and $10-30 \%$ for subgrade as reported by [36]. The reference mix cured for 28 days of curing satisfy the requirement of the bearing ratio mentioned above.

In the absence of models for predicting the bearing ratio for the flyash-lime-phosphogypsum composite, it was thought pertinent to check the validation of the empirical model (Eq. (4)) proposed for flyash-lime-gypsum mix by [16] on the experimental results obtained in the present study.

$$
B R=2.1736 * q u^{0.5149}
$$

The results are shown in Fig. 12 for the reference mix cured with burlap method of curing. It is evident from this figure that predicted values of bearing ratio is less than the bearing ratio obtained in the current study. This under estimation of the bearing ratio using empirical model reported by [16] is attributed to the difference in curing procedure adopted and materials used.

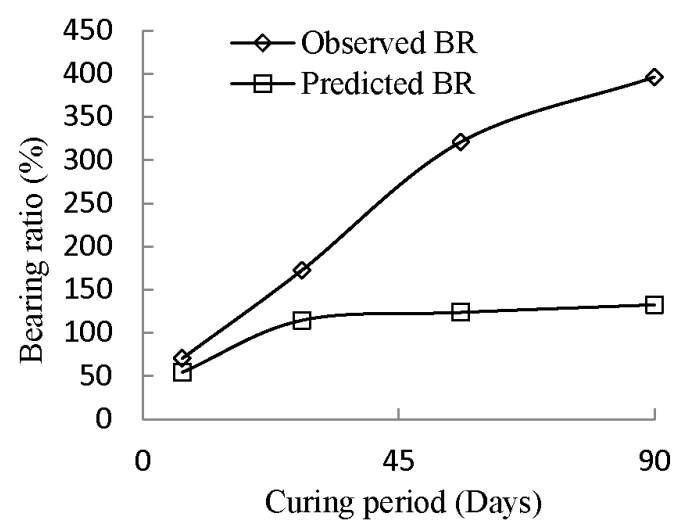

Fig. 12. Variation of predicted and observed bearing ratio with curing period for the reference mix cured with burlap curing method

\subsection{Mineralogy and Morphology}

In order to study the improvement in unconfined compressive strength of the reference mix and to identify the formation of crystalline phases, the $X R D$ and SEM examination was carried out. The maximum strength in unconfined compressive strength was observed when the specimen was cured for 90 days. Therefore, the failed specimen of the reference mix cured for 7, 28, 56 and 90 days was used for XRD and SEM analysis.

\subsubsection{XRD Analysis}

The results of $X R D$ of the reference mix cured for 7 days are shown in Fig. 13. A study of Fig. 13 reveals the emergence of new peaks of ettringite (AFt) positioned at about 9 (2 Theta), calcium-silicate-hydrate (CSH1) positioned at about 30 (2Theta), Aluminium hydroxide (AH) positioned at about $32^{0}$ (2Theta), Calcium silicate (CSI) positioned at about 39, 42 ( 2 Theta) and another peak of Quartz (Q) positioned at about $50^{\circ}$ (2Theta). Contrary to this, no such peak of AFt, CSH1, $\mathrm{AH}, \mathrm{CSI}$ and $\mathrm{Q}$ were observed in the fly ash as evident from Fig.1 (a). The improvement in unconfined compressive strength of the reference mix at 7 days of curing is attributed to the emergence of these new peaks. Diffractogram shown in Fig. 13 also shows low-intensity peaks which may be formed perhaps due to poor crystallinity or due to a lower volume fraction of some of the phases present in the specimen. Apart from the peaks that appeared in the diffractogram, there are certain other noncrystalline products that could not be identified and might have been resulted due to impurities in fly ash and phosphogypsum. The study of diffractogram at 28 days of curing reveals the increase in intensity of ettringite peak positioned at about 9 in comparison to the diffractogram of specimen cured for 7 days.

The improvement in unconfined compressive strength at 28 days of curing is attributed to the increase in the intensity of ettringite (AFt). Further study of diffractogram for the specimen cured for 56 days reveal that there is an increase in the intensity of ettringite (AFt) positioned at about $9^{0}$ (2Theta), CSH1 and Quartz peak positioned at about $30^{\circ}$ (2Theta) and $50^{\circ}$ (2Theta) respectively. The improvement in unconfined compressive strength of the reference mix cured for 56 days is at- 


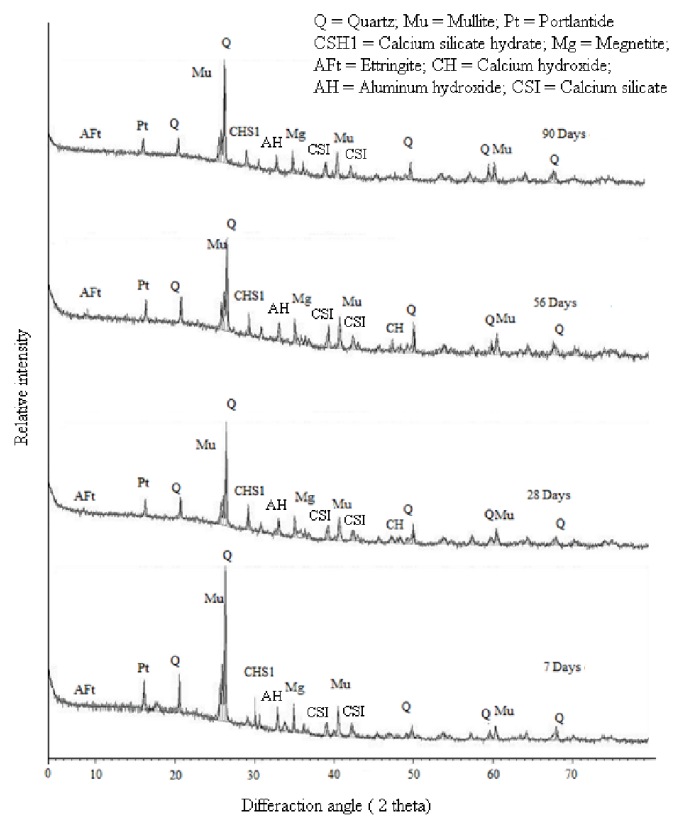

Fig. 13. X-Ray diffractogram of the reference mix at different curing periods

tributed to increase in the intensity of peaks as mentioned above. A close examination of the diffractogram for the specimen cured for 90 days reveal that there is a decrease in the intensity of CSH1 and Quartz peak positioned at about $30^{\circ}$ (2Theta) and $50^{\circ}$ (2Theta) respectively. The slow improvement in unconfined compressive strength from 56 days to 90 days as pointed out in section 4.2 is attributed to the decrease in the intensity of CSH1 and Quartz peak positioned at about $30^{\circ}$ (2Theta) and $50^{\circ}$ (2Theta) respectively.

\subsubsection{SEM Analysis}

The scanning electron micrograph $(S E M)$ at 7 days of curing for the reference mix is shown in Fig. 14.a). A study of this figure reveals that there is bonding among fly ash particles along with formation of ettringite on the surface of fly ash particles. Contrary to this, SEM of fly ash as shown in Fig. 22 a), there was no bonding among flyash particles as well as no emergence of ettringite on the surface of fly ash particles. With the increase in curing period to 28 days and 56 days as shown in Fig. 14(b) and Fig. 14 (c) respectively, there is an improvement in bonding, enhancement of ettringite leading to increase in unconfined compressive strength as experimentally observed in Fig. 5. Further, with the increase in curing period to 90 days as shown in Fig. 14(d), the growth of ettringite filling the void spaces among fly ash particles leading to improvement in unconfined compressive strength.

\subsection{Proposed Correlations}

The correlation among the different parameters studied for the reference mix cured for 7 to 90 days with burlap method of curing were developed using the results of unconfined compressive strength, tensile strength, slake durability indices, bearing ratio tests conducted on the reference mix. The experimental

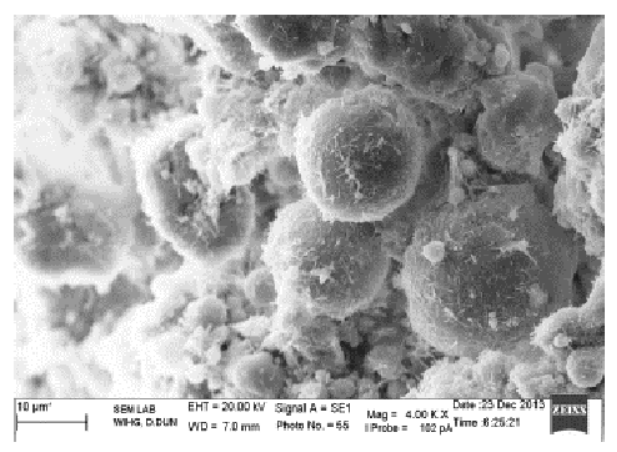

(a)

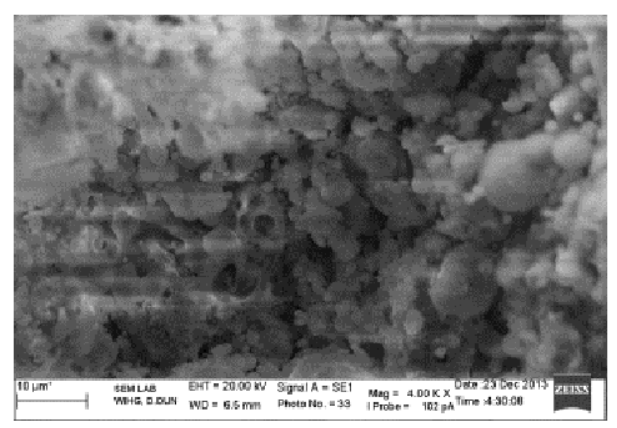

(b)

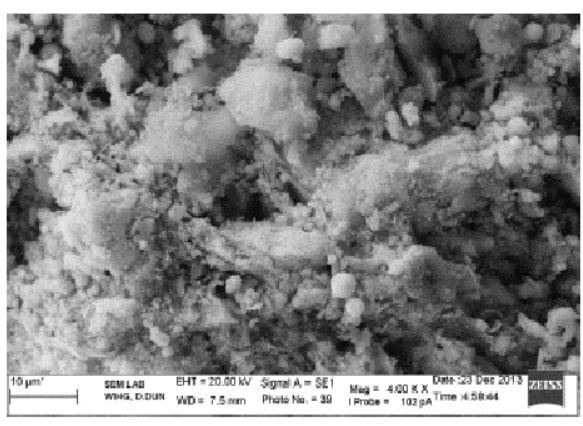

(c)

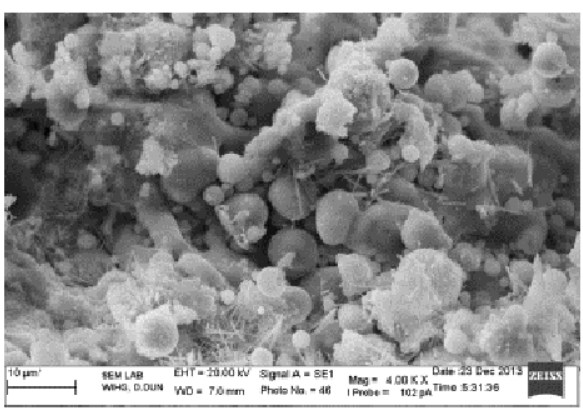

(d)

Fig. 14. SEM Photograph of the reference mix at(a) 7 days $(20 \mathrm{KV}, \mathrm{X} 4000$, $10 \mu$ )(b) 28 days $(20 \mathrm{KV}, \mathrm{X} 4000,10 \mu)$ (c) 56 days $(20 \mathrm{KV}, \mathrm{X} 4000,10 \mu)$ (d) 90 days $(20 \mathrm{KV}, \mathrm{X} 4000,10 \mu)$ 
data obtained from the unconfined compressive strength, tensile strength, slake durability indices, bearing ratio tests were used to develop the regression models using multiple regression analysis. Method of multiple regression analysis, indices for model assessment such as $R^{2} R_{\text {adjusted, }}^{2}$ inferences of multiple regression coefficients and selection of best "fit" regression models are discussed in detail by [37]. The corresponding coefficient of multiple determinations $\left(\mathrm{R}^{2}\right)$, adjusted coefficients of determination $\left(\mathrm{R}_{\text {adjusted }}^{2}\right)$, standard error (SE), and confidence level (CL) are also reported. The multiple regression analysis was carried out by using STATISTICA software version 8 .

4.7.1 Empirical Models to Predict the Tensile Strength, Slake Durability Indices, Bearing Ratio from Unconfined Compressive Strength

In order to assess the strength of a stabilized material, it is common practice to conduct an unconfined compression strength test. For application of the stabilized material in construction of road bases/subbases, tensile strength, slake durability and bearing ratio requirements need to be satisfied in order to justify the suitability of the material. Based on the experimental results reported in the previous sections, an attempt has been made in this section to develop empirical models for the field engineers to make the preliminary estimate of various parameters (tensile strength, slake durability indices and bearing ratio) of the reference mix from the unconfined compressive strength.

4.7.1.1 Tensile strength The scatter plot of tensile stress with unconfined compressive strength at different curing period for the reference mix cured for 7 to 90 days with burlap method of curing is shown in Fig. 15. The basic form of the regression equation was decided on the basis of the study of the scatter plot shown in Fig. 15. Based on the regression analysis, the Eq. (5) is proposed to determine the tensile strength from the unconfined compressive strength.

$$
T S=1.97 * 10^{-5} q_{u}^{2.32}
$$

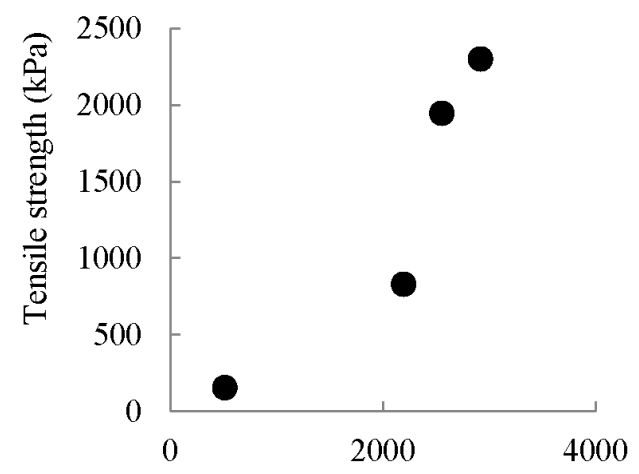

Unconfined compressive strength $(\mathrm{kPa})$

Fig. 15. Scatter plot of tensile strength with unconfined compressive strength at different curing period for the reference mix cured for 7, 28, 56 and 90 days

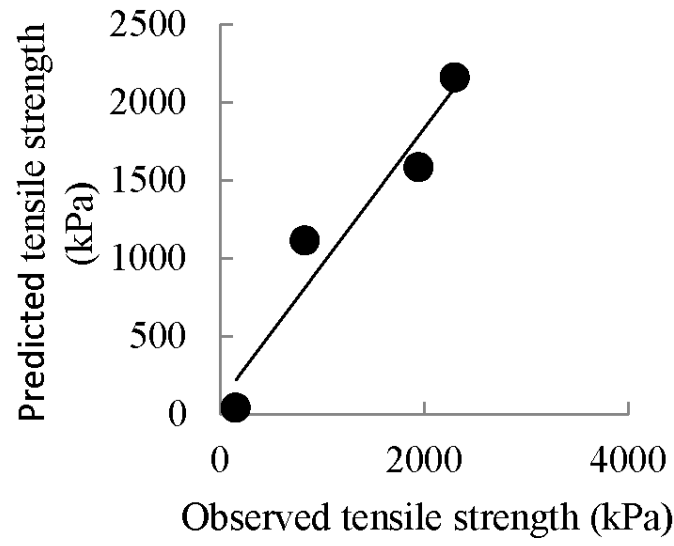

Fig. 16. Plot of observed tensile strength with predicted tensile strength obtained from regression model

The values of the relevant statistical coefficients like coefficient of multiple determinations $\left(R^{2}\right)$, adjusted coefficient of multiple determination $\left(R_{\text {adjusted }}^{2}\right)$, estimated standard error (SE) and confidence level $(C L)$ are $0.93,0.89,319.71$ and $95 \%$, respectively. Fig. 16 presents the observed and predicted tensile strength obtained from the regression model (Eq. (5)). It is evident from this figure, that there is good agreement between the experimental and the predicted values of tensile strength.

4.7.1.2 Bearing ratio The scatter plot of bearing ratio with unconfined compressive strength at different curing period for the reference mix cured for 7 to 90 days with burlap curing method shown in Fig. 17

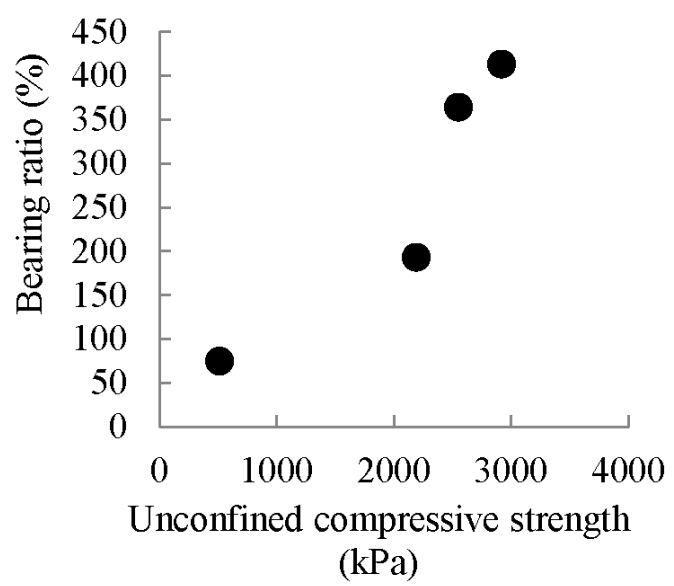

Fig. 17. Scatter plot of bearing ratio with unconfined compressive strength at different curing period for the reference mix cured for 7, 28, 56 and 90 days

The basic form of the regression equation was decided on the basis of the study of the scatter plot shown in Fig. 17. In view of the above, a power model has been chosen for bearing ratio in terms of unconfined compressive strength and the developed equation is shown in Eq. (6).

$$
B R=2.65 * 10^{-4} q_{u}^{1.776}
$$

The values of the relevant statistical coefficients like coefficient of multiple determinations $\left(R^{2}\right)$, adjusted coefficient of multiple determination $\left(R_{\text {adjusted }}^{2}\right)$, estimated standard error $(S E)$ 


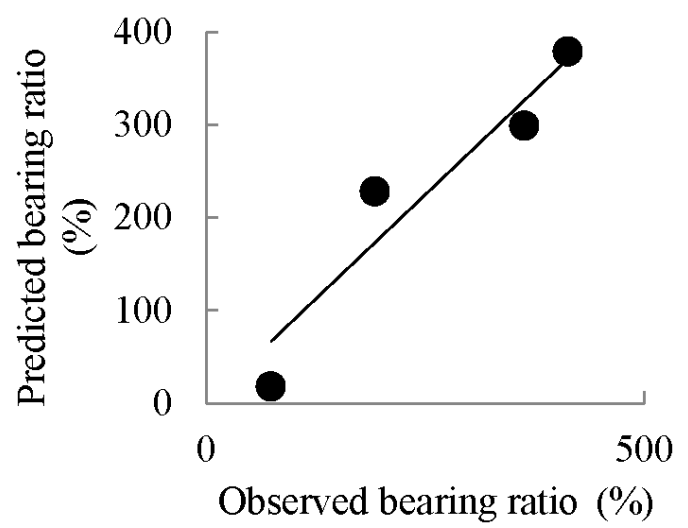

Fig. 18. Plot of observed bearing ratio with predicted bearing ratio obtained from regression model

and confidence level $(C L)$ are $0.89,0.89,57.86$ and $95 \%$, respectively. Fig. 18 presents the observed and predicted bearing ratio obtained from the regression model (Eq. (6)). It is evident from this figure, that there is good agreement between the experimental and the predicted values of bearing ratio.

4.7.1.3 Slake durability index, $I_{\mathrm{d}}(1)$ The scatter plot of slake durability index, $\mathrm{I}_{d}(1)$ with unconfined compressive strength at different curing period for the reference mix cured for 7 to 90 days with burlap curing method shown in Fig. 19 The basic form of the regression equation was decided on the basis of the study of the scatter plot shown in Fig. 19. In view of the above a power model has been chosen for the regression analysis for predicting the slake durability index, $\mathrm{I}_{d}(1)$ in terms of unconfined compressive strength and is shown in Eq. 77.

$$
I_{d}(E q .(1))=49.86 q_{u}^{8.607 * 10-2}
$$

The values of the relevant statistical coefficients like coefficient of multiple determinations $\left(R^{2}\right)$, adjusted coefficient of multiple determination $\left(R_{\text {adjusted }}^{2}\right)$, estimated standard error $(S E)$ and confidence level $(C L)$ are $0.98,0.97,0.98$ and $95 \%$, respectively. Fig. 20 presents the observed and predicted slake durability index, $\mathrm{I}_{d}(1)$ obtained from the regression model (Eq. (7)). It is evident from this figure, that there is good agreement between the experimental and the predicted values of slake durability in$\operatorname{dex}, \mathrm{I}_{d}(1)$.

4.7.1.4 Slake durability index, $I_{\mathrm{d}}(2)$ The scatter plot of slake durability index, $\mathrm{I}_{d}(2)$ with unconfined compressive strength at different curing period for the reference mix cured for 7 to 90 days with burlap curing method shown in Fig. 21 . The basic form of the regression equation was decided on the basis of the study of the scatter plot shown in Fig. 21. In view of the above a power model has been chosen for slake durability index, $\mathrm{I}_{d}(2)$ in terms of unconfined compressive strength and the regression equation is shown in Eq. (8).

$$
I_{d}(2)=46.94 q_{u}^{8.76 * 10-2}
$$

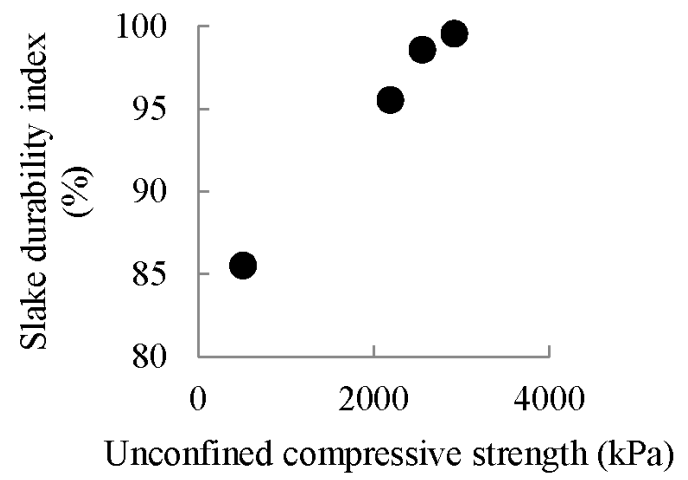

Fig. 19. Scatter plot of slake durability index, $\mathrm{I}_{d}(1)$ with unconfined compressive strength at different curing period for the reference mix cured for 7,28 , 56 and 90 days

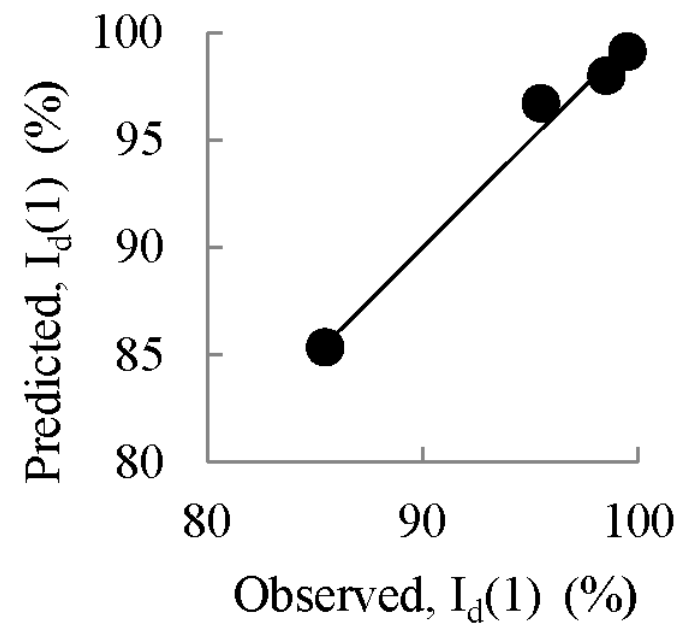

Fig. 20. Plot of observed slake durability index, $\mathrm{I}_{d}(1)$ with predicted slake durability index, $\mathrm{I}_{d}(1)$ obtained from regression model

The values of the relevant statistical coefficients like coefficient of multiple determinations $\left(R^{2}\right)$, adjusted coefficient of multiple determination $\left(R_{\text {adjusted }}^{2}\right)$, estimated standard error $(S E)$ and confidence level $(C L)$ are $0.63,0.44,5.74$ and $95 \%$, respectively. Fig. 22 presents the observed and predicted slake durability index, $\mathrm{I}_{d}(2)$ obtained from the regression model (Eq. (8)).

It is evident from this figure, that there is good agreement between the experimental and the predicted values of slake durability index, $\mathrm{I}_{d}(2)$.

\subsubsection{Empirical Models to Predict the Bearing Ratio and Slake Durability Indices from Tensile Strength}

Based on the experimental results reported in the previous sections, an attempt has been made in this section to develop empirical models for the field engineers to make the preliminary estimate of various parameters (slake durability indices and bearing ratio) of the reference mix from the tensile strength. Factors like curing period are not taken into consideration directly in developing these regression models. The effect of this parameter (curing period) is indirectly taken by including the values of tensile strength corresponding to the required curing period. 


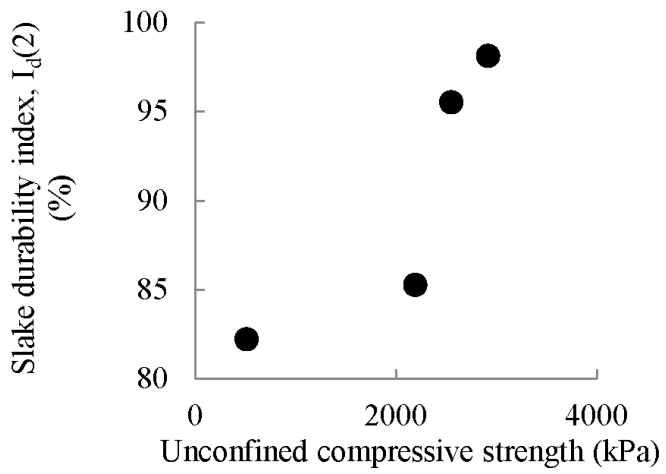

Fig. 21. Scatter plot of slake durability index, $I_{d}(2)$ with unconfined compressive strength at different curing period for the reference mix cured for 7, 28, 56 and 90 days

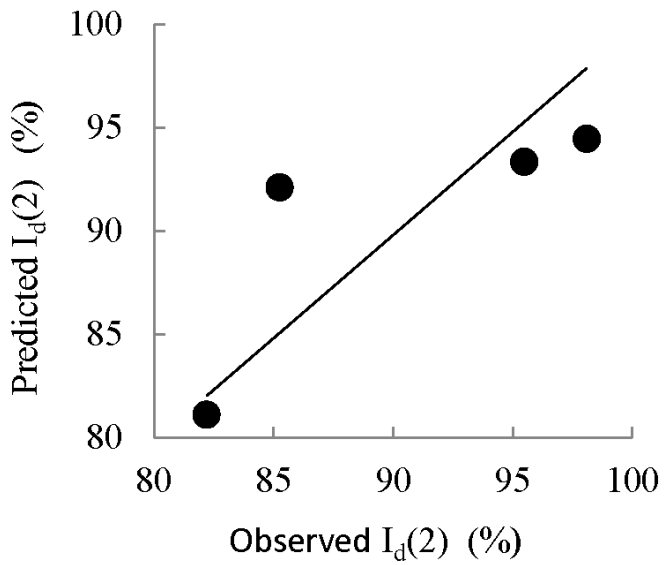

Fig. 22. Plot of observed slake durability index $\mathrm{I}_{d}(2)$ with predicted slake durability index $\mathrm{I}_{d}(2)$ obtained from regression model

4.7.2.1 Bearing ratio The scatter plot of bearing ratio with tensile strength at different curing period for the reference mix cured for 7 to 90 days with burlap curing method shown in Fig. 23. The basic form of the regression equation was decided on the basis of the study of the scatter plot shown in Fig. 23 In view of the above a power model has been chosen for bearing ratio in terms of tensile strength and the regression equation is shown in Eq. (9).

$$
B R=1.361 T S^{0.7277}
$$

The values of the relevant statistical coefficients like coefficient of multiple determinations $\left(R^{2}\right)$, adjusted coefficient of multiple determination $\left(R_{\text {adjusted }}^{2}\right)$, estimated standard error $(S E)$ and confidence level $(C L)$ are 0.98, 0.97, 20.96 and 95\%, respectively. Fig. 24 presents the observed and predicted bearing ratio obtained from the regression model (Eq. 99). It is evident from this figure, that there is good agreement between the experimental and the predicted values of bearing ratio.

4.7.2.2 Slake durability index, $I_{\mathrm{d}}(1)$ The scatter plot of slake durability index, $\mathrm{I}_{d}(1)$ with tensile strength at different curing period for the reference mix cured for 7 to 90 days with burlap curing method shown in Fig. 25. The basic form of the regression equation was decided on the basis of the study of the

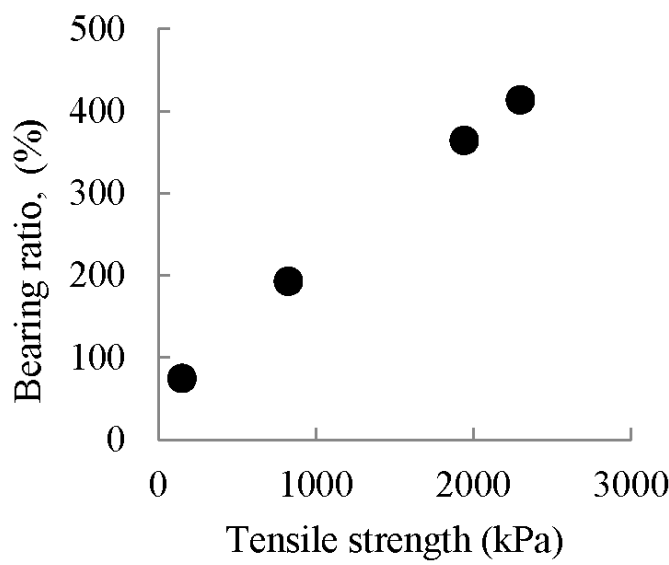

Fig. 23. Scatter plot of bearing ratio with tensile strength at different curing period for the reference mix cured for 7, 28, 56 and 90 days

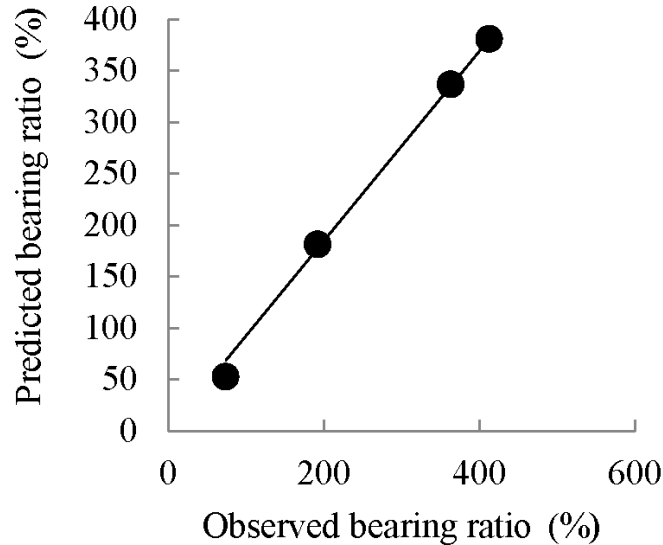

Fig. 24. Plot of observed bearing ratio with predicted bearing ratio obtained from regression model

scatter plot shown in Fig. 25. In view of the above a power model has been chosen for slake durability index,

$\mathrm{I}_{d}(1)$ in terms of tensile strength and the regression equation is shown in Eq. (10).

$$
I_{d}(1)=65.164 * T S^{5.513 * 10-2}
$$

The values of the relevant statistical coefficients like coefficient of multiple determinations $\left(R^{2}\right)$, adjusted coefficient of multiple determination $\left(R_{\text {adjusted }}^{2}\right)$, estimated standard error $(S E)$ and confidence level $(C L)$ are $0.98,0.97,0.92$ and 95\%, respectively. Fig. 26 presents the observed and predicted slake durability index, $\mathrm{I}_{d}(1)$ obtained from the regression model (Eq. (10)). It is evident from this figure, that there is good agreement between the experimental and the predicted values slake durability index, $\mathrm{I}_{d}(1)$.

4.7.2.3 Slake durability index, $I_{\mathrm{d}}(2)$ The scatter plot of slake durability index, $\mathrm{I}_{d}(2)$ with tensile strength at different curing period for the reference mix cured for 7 to 90 days with burlap curing method shown in Fig. 27 The basic form of the regression equation was decided on the basis of the study of the scatter plot shown in Fig. 27. In view of the above a power model has been chosen for slake durability index, $\mathrm{I}_{d}(2)$ in 


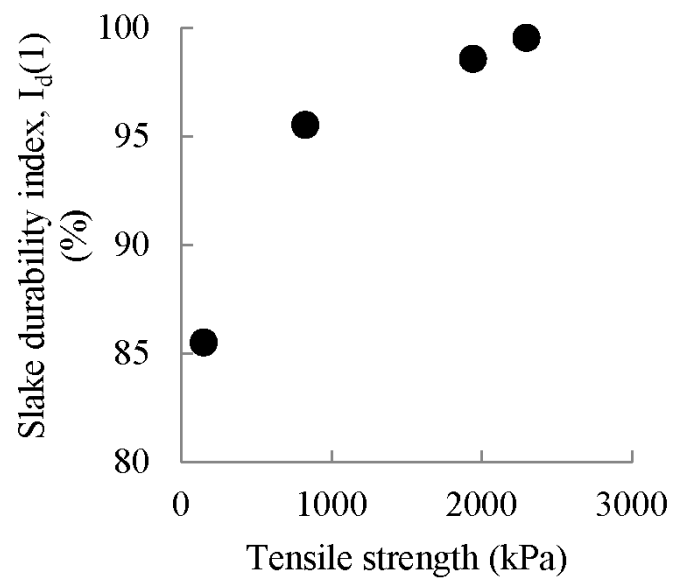

Fig. 25. Scatter plot of slake durability index, $\mathrm{I}_{d}(1)$ with tensile strength at different curing period for the reference mix cured for 7, 28, 56 and 90 days

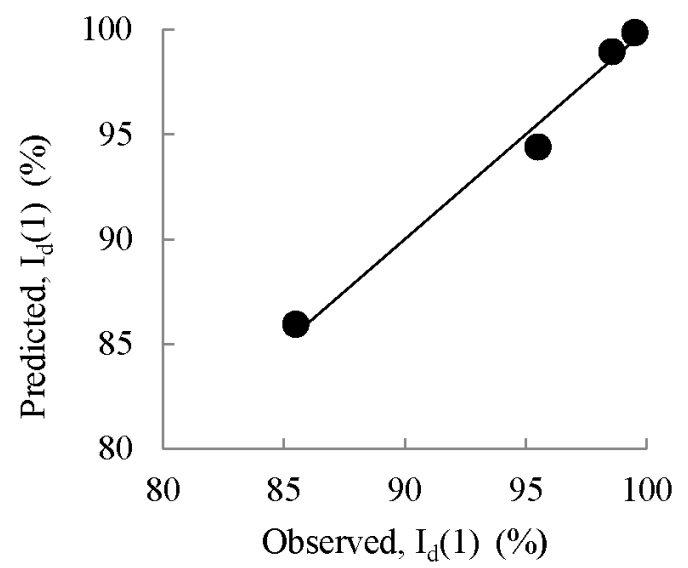

Fig. 26. Plot of observed slake durability index, $I_{d}(1)$ with predicted slake durability index, $\mathrm{I}_{d}(1)$ obtained from regression model

terms of tensile strength and the regression equation is shown in Eq. (11).

$$
I_{d}(2)=57.89 T S^{6.53 * 10-2}
$$

The values of the relevant statistical coefficients like coefficient of multiple determinations $\left(R^{2}\right)$, adjusted coefficient of multiple determination $\left(R_{\text {ad justed }}^{2}\right)$, estimated standard error $(S E)$ and confidence level $(C L)$ are $0.83,0.75,3.79$ and $95 \%$, respectively.

Fig. 28 presents the observed and predicted slake durability index, $\mathrm{I}_{d}(2)$ obtained from the regression model (Eq. (11)). It is evident from this figure, that there is good agreement between the experimental and the predicted values slake durability index, $\mathrm{I}_{d}(2)$.

\subsubsection{Empirical Models to Predict the Slake Durability In- dices from Bearing Ratio}

Based on the experimental results reported in the earlier section, an attempt has been made in this section to develop empirical models for the field engineers to make the preliminary estimate of various parameters (slake durability indices) of the reference mix from the bearing ratio. Factors like curing period are not taken into consideration directly in developing these re-

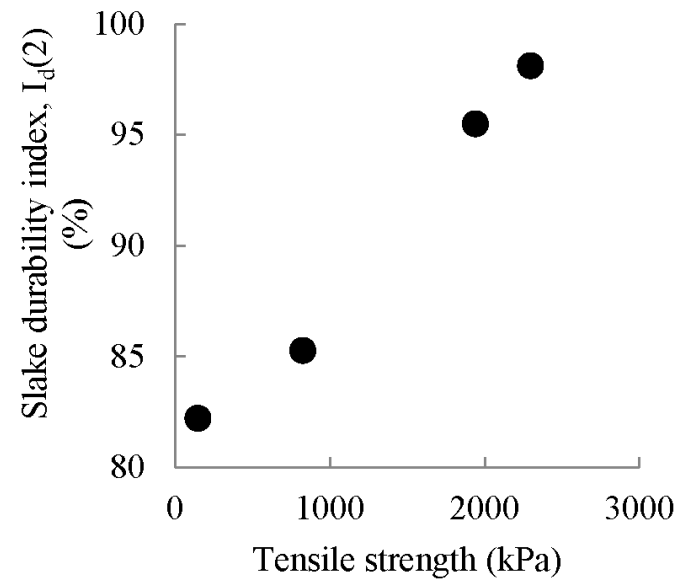

Fig. 27. Scatter plot of slake durability index, $\operatorname{Id}(2)$ with tensile strength at different curing period for the reference mix cured for 7, 28, 56 and 90 days

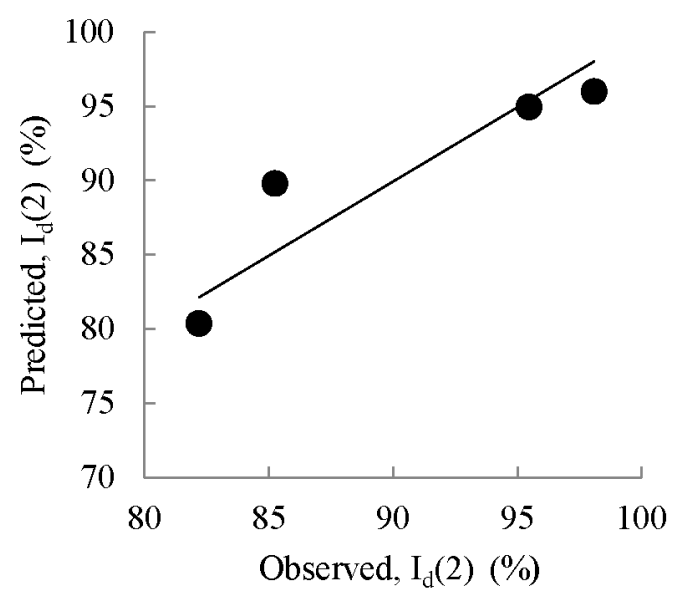

Fig. 28. Plot of observed slake durability index, $I_{d}(2)$ with predicted slake durability index, $\mathrm{I}_{d}(2)$ obtained from regression model

gression models. The effect of this parameter (curing period) is indirectly taken by including the values of bearing ratio corresponding to the required curing period.

4.7.3.1 Slake durability index, $I_{\mathrm{d}}(1)$ The scatter plot of slake durability index, $\mathrm{I}_{d}(1)$ with bearing ratio at different curing period for the reference mix cured for 7 to 90 days with burlap curing method shown in Fig. 29. The basic form of the regression equation was decided on the basis of the study of the scatter plot shown in Fig. 29.

In view of the above a power model has been chosen for slake durability index, $\mathrm{I}_{d}(1)$ in terms of bearing ratio and the regression equation is shown in Eq. (12)

$$
I_{d}(1)=60.04 B R^{8.6007 * 10-2}
$$

The values of the relevant statistical coefficients like coefficient of multiple determinations $\left(R^{2}\right)$, adjusted coefficient of multiple determination $\left(R_{\text {adjusted }}^{2}\right)$, estimated standard error $(S E)$ and confidence level $(C L)$ are $0.95,0.92,1.73$ and $95 \%$, respectively.

Fig. 30 presents the observed and predicted slake durability index, $\mathrm{I}_{d}(1)$ obtained from the regression model (Eq. (12)). It is 


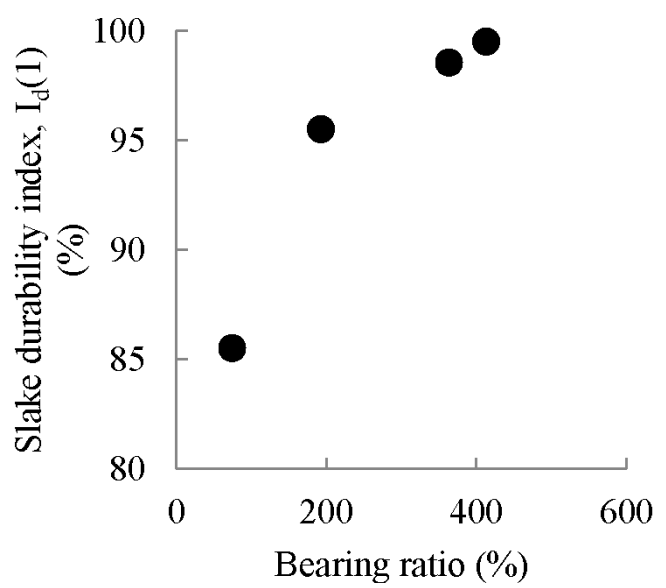

Fig. 29. Scatter plot of slake durability index, $\mathrm{I}_{d}(1)$ with bearing ratio at different curing period for the reference mix cured for 7, 28, 56 and 90 days

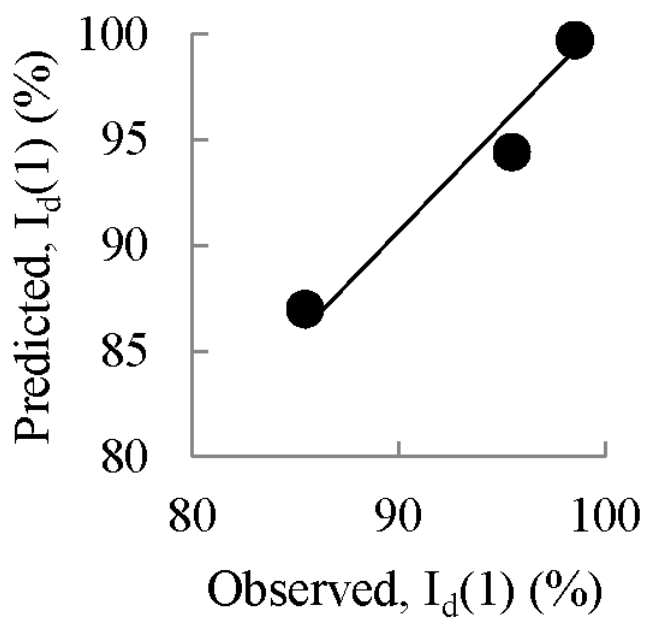

Fig. 30. Plot of observed slake durability index, $\mathrm{I}_{d}(1)$ with predicted slake durability index, $\mathrm{I}_{d}(1)$ obtained from regression model

evident from this figure, that there is good agreement between the experimental and the predicted values of slake durability in$\operatorname{dex}, \mathrm{I}_{d}(1)$.

4.7.3.2 Slake durability index, $I_{\mathrm{d}}(2)$ The scatter plot of slake durability index, $\mathrm{I}_{d}(2)$ with bearing ratio at different curing period for the reference mix cured for 7 to 90 days with burlap curing method shown in Fig. 31 The basic form of the regression equation was decided on the basis of the study of the scatter plot shown in Fig. 31. In view of the above a power model has been chosen for slake durability index, $\mathrm{I}_{d}(2)$ in terms of bearing ratio and the regression equation is shown in Eq. 13.

$$
I_{d}(2)=50.85 B R^{0.107}
$$

The values of the relevant statistical coefficients like coefficient of multiple determinations $\left(R^{2}\right)$, adjusted coefficient of multiple determination $\left(R_{\text {adjusted }}^{2}\right)$, estimated standard error (SE) and confidence level $(C L)$ are 0.90, 0.86, 2.84 and 95\%, respectively. Fig. 32 presents the observed and predicted slake durability index, $\mathrm{I}_{d}(2)$ obtained from the regression model (Eq. (13)). It is evident from this figure, that there is good agreement between the experimental and the predicted values of slake durability in$\operatorname{dex}, \mathrm{I}_{d}(2)$.

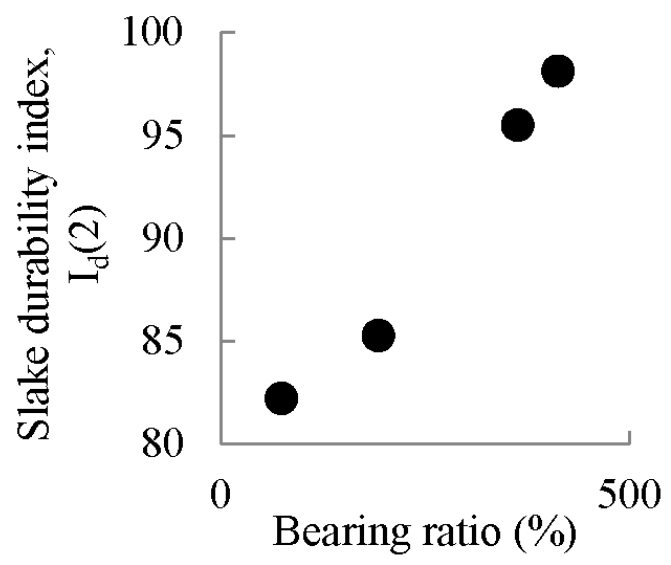

Fig. 31. Scatter plot of slake durability index, $\mathrm{I}_{d}(2)$ with bearing ratio at different curing period for the reference mix cured for 7, 28, 56 and 90 days

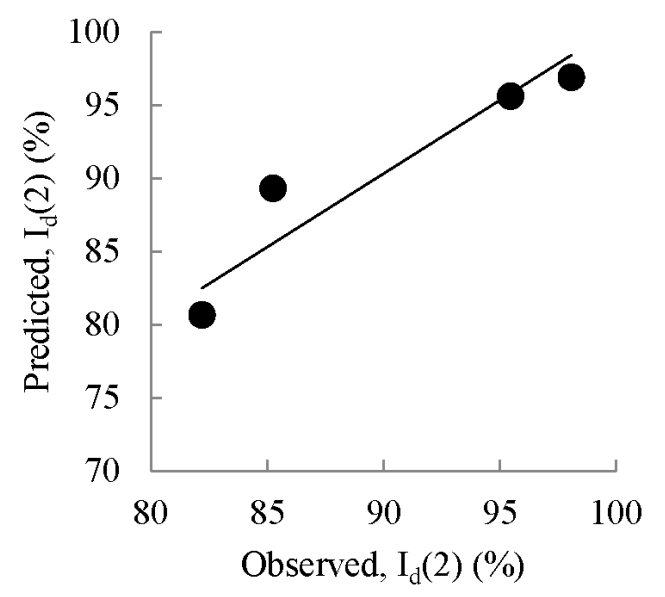

Fig. 32. Plot of observed slake durability index, $I_{d}(2)$ with predicted slake durability index, $\mathrm{I}_{d}(2)$ obtained from regression model

\section{Conclusions}

On the basis of the results and discussion presented in this paper, the following is concluded.

1 The unconfined compressive strength of the flyash-limephosphogypsum composite increased with the increase in curing period. The composite satisfy the requirement of unconfined compressive strength at 28 days of curing.

2 The tensile strength of the flyash-lime-phosphogypsum composite increased with the increase in curing period. The composite satisfy the requirement of tensile strength at 7 days of curing.

3 The slake durability of the flyash-lime-phosphogypsum composite improved with the increase in curing period. The composite satisfy the requirement of slake durability at 28 days of curing.

4 The bearing ratio of the flyash-lime-phosphogypsum composite increased with the increase in curing period. The com- 
posite satisfy the requirement of bearing ratio at 28 days of curing.

5 Good agreement is observed between the experimental values and predicted values for tensile strength, bearing ratio, slake durability indices.

6 The developed models will be useful for making preliminary estimate of these parameters by the field engineers for planning purposes.

7 The empirical models presented are based on the experimental data within the range of parameter (curing period 7 to 90 days) and materials tested. Beyond this range of values the model may be checked with experimental results.

8 The models reported in literature under estimate the properties like bearing ratio, tensile strength and slake durability indices determined from the unconfined compressive strength.

On the whole, this study has attempted to provide the suitability of the flyash-lime-phosphogypsum composite. The composite (flyash $+8 \%$ lime $+2 \%$ phosphogypsum) so developed satisfy the unconfined compressive strength, split tensile strength, and slake durability criteria as well as giving higher bearing ratio at 28 days of curing. The composite can be used as a base/subbase course material in road pavements.

\section{References}

1 Sivapullaiah PV, Moghal AAB, Role of Gypsum in the Strength Development of Fly Ashes with Lime, Journal of Materials in Civil Engineering, 23(2), (2011), 197-206, DOI 10.1061/(ASCE)MT.1943-5533.0000158

2 Mishra M K, Karanam U M R, Geotechnical characterization of fly ash composites for backfilling mine voids, Geotechnical and Geological Engineering, 24(6), (2006), 1749-1765, DOI 10.1007/s1070600668058

3 Ghosh A, Subbarao C, Strength Characteristics of Class F Fly Ash Modified with Lime and Gypsum, Journal of Geotechnical and Geoenvironmental Engineering, 133(7), (2007), 757-766, DOI 10.1061/(ASCE)10900241(2007)133:7(757)

4 Ghosh A, Compaction Characteristics and Bearing Ratio of Pond Ash Stabilized with Lime and Phosphogypsum, Journal of Materials in Civil Engineering, 22(4), (2010), 343-351, DOI 10.1061/(ASCE)MT.1943-5533.0000028

5 Gray DH, Lin YK, Engineering properties of compacted fly ash, Journal of Soil Mechanics and Foundation Division, 98(4), (1972), 361-380.

6 Joshi RC, Duncan DM, McMaster HM, New and conventional engineering uses of fly ash, Transportation Engineering Journal, 101(4), (1975), 791-806.

7 Poran CJ, Ahtchi-Ali F, Properties of Solid Waste Incinerator Fly Ash, Journal of Geotechnical Engineering, 115(8), (1989), 1118-1133, DOI 10.1061/(ASCE)0733-9410(1989)115:8(1118)

8 Croft JB, The pozzolanic reactivities of some new south wales fly ashes and their application to soil stabilization, Australian Road Research Board, 2(2), (1964), 1144-1168.

9 Indraratna B, Nutalaya P, Koo KS, Kuganenthira N, Engineering behaviour of a low carbon, pozzolanic fly ash and its potential as a construction fill, Canadian Geotechnical Journal, 28(4), (1991), 542-555, DOI 10.1139/t91-070

10 Sivapullaiah PV, Prashanth JP, Sridharan A, Narayana BV, Reactive silica and strength of fly ashes, Geotechnical and Geological Engineering, 16(3), (1998), 239-250, DOI 10.1023/A:1008889326269
11 Eades JL, Grim RE, Reaction of hydrated lime with pure clay minerals in soil stabilization, Highway Research Bulletin No. 262, Highway Research Board, Washington, D.C., (1960), 51-63.

12 Aimin. X, Sarkar SL, Microstructural study of gypsum activated fly ash hydration in cement paste, Cement and Concrete Research, 21(6), (1991), 1137-1147, DOI 10.1016/0008-8846(91)90074-R

13 Sánchez de Rojas MI, Luxán MP, Frías M, García N, The influence of different additions on portland cement hydration heat, Cement and Concrete Research, 23(1), (1993), 46-54, DOI 10.1016/0008-8846(93)90134-U

14 Ghosh A, Subbarao C, Microstructural Development in Fly Ash Modified with Lime and Gypsum, Journal of Materials in Civil Engineering, 13(1), (2001), 65-70, DOI 10.1061/(ASCE)0899-1561(2001)13 1(65)

15 Das SK, Yudbhir, Geotechnical Characterization of Some Indian Fly Ashes, Journal of Materials in Civil Engineering, 17(5), (2005), 544-552, DOI 10.1061/(ASCE)0899-1561(2005)17 5(544)

16 Ghosh A, Subbarao C, Tensile Strength Bearing Ratio and Slake Durability of Class F Fly Ash Stabilized with Lime and Gypsum, Journal of Materials in Civil Engineering, 18(1), (2006), 18-27, DOI 10.1061/(ASCE)08991561(2006)18 1(18)

17 Sobhan K, Mashnad M, Tensile Strength and Toughness of Soil-Cement-Fly-Ash Composite Reinforced with Recycled High-Density Polyethylene Strips, Journal of Materials in Civil Engineering, 14(2), (2002), 177-184, DOI 10.1061/(ASCE)0899-1561(2002)14:2(177)

18 Maher M H, Balaguru P N, Properties of Flowable High-Volume Fly AshCement Composite, Journal of Materials in Civil Engineering, 5(2), (1993), 212-225, DOI 10.1061/(ASCE)0899-1561(1993)5:2(212)

19 Das BM, Yen SC, Dass RN, Brazilian tensile strength test of lightly cemented sand, Canadian Geotechnical Journal, 32(1), (1995), 166-171, DOI 10.1139/t95-013

20 Consoli NC, Montardo JP, Prietto PDM, Pasa G P, Engineering Behavior of a Sand Reinforced with Plastic Waste, Journal of Geotechnical and Geoenvironmental Engineering, 128(6), (2002), 462-472, DOI 10.1061/(ASCE)1090-0241(2002)128:6(462)

21 Ghosh A, Environmental and engineering characteristics of stabilized lowlime fly ash, PhD thesis, Indian Institute of Technology; Kharagpur, India, 1996.

22 Dempsey BJ, Thomson MR, Effect of Freeze - Thaw parameters on the durability of stabilized materials, Transportation Engineering Series no 4, Illinois cooperative highway research program series no 136 , report project IHR-401; university of Illinois, Urbana, Illinois, 1973, http://ict. illinois.edu/publications/report\%20files/TES-004.pdf

23 Jha JN, Gill KS, Choudhary AK, Effect of high fraction class $F$ fly ash on lime stabilization of soil, International Journal of Geotechnics and Environment, 1(2), (2009), 105-128.

24 Franklin JA, Chandra R, The slake-durability test, International Journal Rock Mechanics and Mining Sciences \& Geomechanics Abstracts, 9(3), (1972), 325-328, DOI 10.1016/0148-9062(72)90001-0

25 Brown ET (ed.), ISRM, Suggested methods for rock characterization, testing, and monitoring, ISRM Commission on Testing Methods; Pergamon, Tarrytown, N.Y., 1981.

26 Kumar S, A perspective study on fly ash-lime-gypsum bricks and hollow blocks for low cost housing development, Construction and Building Materials, 16(8), (2002), 519-525, DOI 10.1016/S0950-0618(02)00034-X

27 Singh M, Garg M, Durability of cementing binders based on fly ash and other wastes, Construction and Building Materials, 21(11), (2007), 2012 2016, DOI 10.1016/j.conbuildmat.2006.05.032

28 Determination of water content dry density relation using light compaction, Bureau of Indian Standards; Compendium of Indian Standard on Soil Engineering, IS 2720, Part 7, New Delhi, India, 1980.

29 Determination of slake durability index of rocks (reaffirmed in 2001), Bureau of Indian Standards; IS: 10050, New Delhi, India, 1981. 
30 Dutta RK, Guleria SP, Effect of addition of tire chips on the unconfined compressive strength of fly ash-lime-gypsum mixture, International Journal of Geotechnical Engineering, 6(1), (2012), 1-13, DOI 10.3328/IJGE.2012.06.01.1-13

31 Maclean DJ, Robinson PJM, Methods of soil stabilization and their application to the construction of Airfield Pavement, ICE Proceedings: Engineering Divisions, 2(3), (1953), 447-486.

32 Franklin JA, Dusseault MB, Rock engineering, International Ed., McGrawHill; New York, 1989.

33 Ádány S, Guide to Stabilisation in Roadworks, National Association of Australian State Road Authorities (NAASRA), Sydney, Replaced in 1998 by AP-60/98, Austroads, 1986, http://nzta.govt.nz/resources/ austroads-guide-stabilisation-roadworks/index.html

34 Goodman RE, Introduction to rock mechanics, 2nd Ed., Wiley; New York, 1989.

35 Nigerian general specification for roads and bridges, Federal Ministry of Works and Housings, 1997, Abuja, Nigeria, 13\T1\textendash25, http://www.scribd.com/doc/40333915/General-Specifications

36 Edeh JE, Agbede IO, Tyoyila A, Evaluation of Sawdust Ash-Stabilized Lateritic Soil as Highway Pavement Material, Journal of Materials in Civil Engineering, 26(2), (2014), 367-373, DOI 10.1061/(ASCE)MT.19435533.0000795

37 Bera AK, Chandra SN, Ghosh A, Ghosh A, Unconfined compressive strength of fly ash reinforced with jute geotextiles, Geotextiles and Geomembranes, 27(5), (2009), 391-398, DOI 10.1016/j.geotexmem.2008.12.004 